\title{
한국의 국제개발협력 인지제고 및 교육현황과 과제 ${ }^{11}$
}

\author{
이 상 백 KOICA 민간협력팀 대리
}

\section{I. 서론}

대한민국은 급속한 경제성장과 민주주의의 발전에 힘입어, 원조를 받아오던 수원국(Recipient Country) 입장에서 벗어나 신흥 원조공여국(Emerging Donor)으로서의 역할을 수행하기 시작하 였다. 또한 최근에는 국내외적으로 세계 12 위권의 경제규모에 걸맞는 국제사회에 대한 기여와 공적 개발원조에 대한 양적 · 질적 개선을 요구받고 있다. ${ }^{2}$

그러나, 이러한 국제사회에서의 대한민국의 역할에 대한 국내외적 기대와 요청, 그리고 국제개발협 력 분야에 대한 국민적 관심이 높아져가고 있음에도 불구하고 아직까지 국제개발협력에 대한 인식 과 이를 위한 교육수준이 초기 단계에 있음을 부인할 수 없다. 국민의 관심과 이해, 그리고 지지를 바탕으로 하지 않고서는 공적개발원조 규모의 확대와 질적 개선을 담보할 수 없다는 점을 생각해볼 때, 국제개발협력 분야에 대한 인지제고와 이를 위한 개발협력 교육의 필요성과 중요성이 더해져가 고 있다.

영국과 아일랜드, 네덜란드를 비롯한 서구의 대부분 선진 공여국들에서는 일찍부터 개발협력 분야 에 대한 인지제고 프로그램들과 또 이를 위한 교육프로그램들이 활발하게 진행되고 있으며이으르른 바탕으로 개발협력에 대한 높은 관심과 지지를 보이고 있어 우리와는 사뭇 상당한 차이가 있어 보 인다.

이러한 때, 2009년부터 한국국제협력단(KOICA)에서 국제개발협력에 대한 국민의 이해와 지지를

1) 본 기고문은 2009.5.17일 광주 국제포럼 <한국 ODA의 새로운 지평을 열기 위한 시민사회의 도전>에서 발표된 「국제개 발협력 시민교육 현황과 과제」를 수정 보완하였다.

2) $\mathrm{OECD}$ 개발원조위원회(DAC)의 특별검토(보고서) 권고 사항

3) 영국은 Development Awareness Funding Scheme, 아일랜드는 Development Education Funding Scheme 을 각각 운영 하면서, 개발인지 프로그램과 교육프로그램을 지원해오고 있다. 
제고하고, 국민의 세계시민의식을 함양하기 위한 “국제개발협력 인지강화 프로그램” 이 실시되기 시작하였다는 것은 시의적절하고 고무적인 일이라 할 수 있다. 또한, 최근 한국사회에서는 민간단 체(NGO)를 중심으로 공적개발원조(ODA) 또는 국제개발협력 관련 교육 프로그램과 세계시민교육 이 활발하게 운영되기 시작하고 있어 ${ }^{4)}$ 그 전망이 전혀 어둡다고 보기는 어렵다.

이 글에서는 먼저 한국의 국제개발협력에 대한 인지정도를 바탕으로, 지금까지 한국 정부와 시민사 회에서 진행되고 있는 국제개발협력 분야 인지제고 및 교육프로그램에 대한 현황을 살펴보고, 이를 바탕으로 국제개발협력 인지제고 및 개발협력 교육이 나아갈 방향히에 대해 모색해 보고자 한다.

\section{II. 한국의 국제개발협력에 대한 인지수준}

본격적으로 한국의 국제개발협력 분야 인지제고 노력 및 교육현황을 살펴보기에 앞서, 우선 공적개 발원조를 중심으로 국제개발협력 분야에 대한 한국 국민들의 인지수준 및 태도에 대해 살펴보자. 2008년 8월 외교통상부가 (사)한국개발전략연구소에 의뢰하여, 전국의 19세 이상 성인 남녀 500 명을 대상으로 $\mathrm{ODA}$ 에 대한 의식 및 태도를 조사한 결과 ${ }^{6)}$, $\mathrm{ODA}$ 인지도와 관련된 질문에 대해 '매 우 잘 알고 있다’ 또는 '알고 있다'고 답한 사람은 $51 \%$ 에 그쳐, 2005 년에 비해 다소 증가하기는 하 였으나, 아직까지 우리나라 국민 중 2 명당 1 명은 $\mathrm{ODA}$ 에 대해 알고 있지 못하거나 들어보기 못한 것으로 드러나고 있다. 또, 한국의 ODA 규모에 대해서는 '현 수준이 적절하다'(44\%)와 '현 수준을 유지해야 한다' $(53.4 \%)$ 는 의견이 다수인 것으로 파악되고 있어, 공적개발원조 규모의 확대와 질적 개선을 위해서는 국민의 지지기반 확보가 절실히 필요함을 잘 드러내고 있다.

〈표 1〉ODA 관련 국민인식조사 2005년 vs 2008년 비교

\begin{tabular}{c|c|c}
\hline 조사내용 & 2005 & 2008 \\
\hline 공적개발원조 제공 사실인지도 & ‘공적개발원조 제공 사실 알고 있다’ & ‘공적개발원조 제공 사실 알고있다’ \\
\hline 개발도상국 대외원조 지지도 & $37.1 \%$ & $51 \%$ \\
\hline 국력감안시 현재 대외원조 규모 평가 & '찬성’ 62.3\% & ‘현규모 적절’ 이상 답변 58\% \\
\hline
\end{tabular}

4) One Heart 굿네이버스 세계시민교육 교재 p14

5) 이 글에서의 개진되는 국제개발협력 인지제고 및 교육 로드맵 등에 대한 의견은 필자의 개인적 의견으로 국제협력단 공식 의견은 아님을 밝혀둔다.

6) 한국개발전략연구소「개발원조에 대한 대국민 여론조사 및 정부의 국제개발협력정책의 방향연구」 


\begin{tabular}{|c|c|c|}
\hline 대외원조의 기여도 평가 & $\begin{array}{c}\text { ‘국제사회 문제해결과 국익에 } \\
\text { 기여한다’ } 59.7 \%\end{array}$ & $\begin{array}{c}\text { ‘국제사회 문제해결과 국익에 } \\
\text { 기여한다' } 72 \%\end{array}$ \\
\hline 중점 지원 지역 & '아프리카 지역' $44.5 \%$ & ‘아프리카 지역’ $81 \%$ \\
\hline 중점 지원 분야 & $\begin{array}{c}\text { ‘아동, 환경, 인권보호’ } 26.4 \% \\
\text { ‘재난구호 및 난민지원 등의 분야’ } 23.3 \%\end{array}$ & $\begin{array}{c}\text { ‘보건 및 의료환경 개선’ } 42 \% \\
\text { '인도적지원' } 18 \%\end{array}$ \\
\hline
\end{tabular}

(자료: 외교통상부/표본오차는 $95 \%$ 신뢰수준에 $\pm 4.38 \%$ )

\section{III. 한국의 국제개발협력 인지제고를 위한 노력}

\section{가. 정부중심의 국제개발협력 교육}

위에서 살펴본 우리나라의 국제개발협력에 대한 낮은 인지정도와 교육 필요성을 바탕으로 이제 본 격적으로 지금까지 우리나라에서 실시되고 있는 국제개발협력에 대한 인지제고 노력과 그 활동에 대해 살펴보자. 국제개발협력 인지제고 노력은 크게 정부가 중심이 되어 시행하고 있는 국제개발협 력 관련 인지제고 및 교육 프로그램들과 민간단체(NGO)를 중심으로 실시되고 있는 시민교육 프로 그램으로 나뉘어 생각해볼 수 있으며, 다시 정부중심의 국제개발협력 교육은 초·중·고등학교 정 규 교과목에서의 국제개발협력 내용 소개와 한국 국제협력단에서 실시되고 있는 국제개발협력 인 지강화 프로그램 등으로 나뉘어 살펴볼 수 있다.

먼저, 초·중·고등학교 공교육 과정 안에서 이루어지고 있는 국제개발협력 교육 프로그램을 살펴 보면, 우선 초·중·고등학교 교과서에 실려 있는 지구촌 시대의 세계시민의식과 관련된 내용과 한 국국제협력단 및 국경없는 의사회, 유니세프 등 비정부기구(NGO) 활동들에 대한 소개를 들 수 있 다. 겅부의 세계시민 의식 및 국제개발협력에 대한 관심과 교육의지는 '7차 교육과정'의 초등학교 교육목표 다항) 다양한 일의 세계를 이해할 수 있는 폭넓은 학습 경험을 가진다와 고등학교 교육목 표 마항) 국가 공동체의 형성과 발전을 위해 노력하며, 세계시민으로서의 의식과 태도를 가진다' 등 에서 엿볼 수 있으며, 이러한 세계시민으로서의 의식 또는 국제개발협력과 관련된 내용은 1997년 제 7 차 교육과정 개정시점부터 초·중 · 고교 교과서에 게제 ${ }^{9)}$ 되기 시작하였다.

7) 7차 교육과정 초등학교 6학년 사회교과서 102 131P. 대한교과서

8) 교육부 고시 1997-15호 제 7차 교육과정 개정/공고

9) 대한교과서, 교학사, 중앙교육 진흥연구소, 지학사, 고려출판 등 (출처: 박수연 등 3인. 2007. 「인도주의적 개발교육을 통 한 ODA 역량강화」 : 제 4회 국제개발협력 논문공모전 우수작) 
다음으로, 한국국제협력단에서 실시하고 있는 국제개발협력 인지제고 프로그램 및 개발협력 교육 과 관련한 노력에 대해 살펴보자. 우선, 한국 국제협력단에서는 초·중· 고등학교 학생에 대한 국 제개발협력 인지제고를 목적으로 공적개발원조(ODA) 및 국제개발협력에 대한 교육, 특강을 실시 해오고 있으며 2008년까지 전국 초·중 · 고등학교 400여개 학교를 대상으로 교육, 특강을 실시 한 바 있다. ${ }^{10)}$ 또한 국제개발협력 관련 글짓기 대회 ${ }^{11)}$ 및 대학(원)생 대상 국제개발협력 논문대회 ${ }^{12)}$ 를 실시하고 있으며, 수상자에게는 국제개발 협력 현장방문 기회를 제공하는 등 국제개발협력에 대 한 국민의 인식제고와 참여를 확대하고자 노력해오고 있다. 이외에도, 2007과 2008년에는 각각 제 1,2 회 $\mathrm{ODA}$ 국제 컨퍼런스를 성공적으로 주최함으로써, 국민들의 국제개발협력에 대한 인지도 향 상에 크게 기여한 바 있다.

이처럼 한국국제협력단의 국제개발협력에 대한 인지제고 및 교육프로그램에 대한 지원은 지속적으 로 증가하고 있으며, 이러한 국제협력단의 국제개발협력 인지제고 및 교육 프로그램은 올해 2009 년에 들어오면서 “국제개발협력 인지강화 프로그램 ${ }^{13) ”}$ 이라는 이름의 새로운 지원사업을 시작하면 서 새로운 전환기를 맞이하게 되었다.

〈표 2〉개발협력 인지제고를 위한 예산지출

\begin{tabular}{c|c|c|c|c|c|c|c} 
& 2001 & 2002 & 2003 & 2004 & 2005 & 2006 & 2007 \\
$\begin{array}{c}\text { 금액 } \\
\text { (US\$ million) }\end{array}$ & 0.7 & 0.72 & 1.15 & 1.67 & 2.27 & 2.47 & 4.12 \\
\hline $\begin{array}{c}\text { 금액 } \\
(\text { 백만원) }\end{array}$ & 898 & 903 & 1,368 & 1,913 & 2,327 & 2,361 & 3,830 \\
\hline $\begin{array}{c}\text { ODA } \\
\text { 대비 비율(\%) }\end{array}$ & 0.26 & 0.26 & 0.31 & 0.4 & 0.3 & 0.48 & 0.56 \\
\hline
\end{tabular}

(자료 : 한국국제협력단 홈페이지 통계자료)

이번 국제개발협력 인지강화 프로그램은 국민의 개발협력에 대한 이해증진 및 지지기반 확보를 목 적으로, 국제협력단-NGO-대학-연구소 등 다양한 국제개발협력 주체들간의 상호이해와 파트너쉽 강화를 바탕으로 국제개발협력 사업에 대한 민간부문의 참여를 확대하고 나아가 국민의 세계시민 의식 함양을 그 목적으로 하고 있다. ${ }^{14)}$ 구체적 사업내용은 크게 세 가지로 나뉘어 볼 수 있는데 그 주요내용은 다음과 같다.

10) 국제협력단 홍보실 인터뷰 자료

11) 1998년부터 2008년까지 제 11회 글짓기 대회 실시 완료

12) 2008년까지 제 5회 대회를 마치고 2009년 현재 6회 논문대회 (심사중)

13) 국제협력단 민간협력팀에서 주관/실시 2009년 9월 현재 사업진행 중

14) 국제협력단「개발협력 인지강화사업 안내서」참조 
〈표 3〉 2009년 국제개발협력 인지강화 프로그램 주요내용

\begin{tabular}{|c|c|c|c|}
\hline 구 분 & 사업내용 & 사업규모 & 지원방법 \\
\hline $\begin{array}{l}\text { 개발협력 교육 } \\
\text { 컨텐츠 개발 }\end{array}$ & $\begin{array}{c}\text { 개발협력 인지와 교육을 위한 } \\
\text { 컨텐츠 개발 및 강사 Pool 구성· 운영 }\end{array}$ & 1.3억원 & 해외원조단체협의회 위탁 \\
\hline $\begin{array}{c}\text { 민간단체 } \\
\text { 직접 발굴사업 지원 }\end{array}$ & $\begin{array}{l}\text { 국내 개발협력 인지강화를 위해 } \\
\text { 민간단체 직접 사업발굴 지원 }\end{array}$ & 20개사업/3억원 & 공모 및 심사 \\
\hline $\begin{array}{c}\text { 대학교내 교과목으로 국제개 } \\
\text { 발협력과정 개설지원 }\end{array}$ & $\begin{array}{l}\text { 대학교내 교양과목 또는 전공기초과목 } \\
\text { 으로 국제개발협력과정 개설 등 지원 }\end{array}$ & 17 개 대학/3.2억원 & 공모 및 심사 \\
\hline
\end{tabular}

※ 사업규모는 사업 약정체결 기준/정산후 변동 가능

우선 첫 번째 사업으로 국내 개발협력과 관련된 교육 컨텐츠 개발을 들 수 있다. 2008년 국제협력 단에서 「국제개발협력의 이해」 ${ }^{15}$ 라고 하는 국제개발협력 관련 종합서를 발간하긴 하였지만, 아 직까지 우리나라에서는 국제개발협력과 관련하여 제대로 된 교육교재를 보유하지 못하고 있는 것 이 사실이다. 최근 들어 몇몇 단체에서 세계시민교육 교재 ${ }^{16)}$ 를 발간하기 시작하였으나, $\mathrm{NGO단체}$ 들이 발간하는 소식지나 회원가입서류, 브로셔 등이 국제 개발협력 관련 교육 자료의 대부분을 차 지하고 있는 것이 사실이다. 이에 따라 초·중· 고등학교 및 성인들을 대상으로 각 연령대에 맞는 분야별 개발협력 교육자료의 필요성이 대두되었고, 국제협력단에서는 한국 해외원조단체 협의회에 위탁하여 초·중·고등학생용 수준에 맞는 연령대별 국제개발협력 교육자료를 작성중에 있으며, 또한 빈곤, 교육, 여성, 인권, 환경 등 각 분야별 이슈를 포함하는 교육자료를 발간할 예정에 있다. ${ }^{17)}$

국제협력단에서 실시하는 개발협력 인지강화사업의 두 번째는 전국 17 개 대학교에 '국제개발협력 의 이해'라는 내용의 교과목 개설 지원을 들 수 있다. 지금까지 국제개발협력에 대한 교과목 개설은 일부 수도권 대학에서 국제대학원 수업의 일환 ${ }^{18)}$ 으로 실시되어져 왔다. 그러나 이번 국제개발협력 인지강화사업의 시작으로 서울, 경기, 강원, 충청, 전라, 경상도 등 전국 각 지역의 국(공)립대학과

15) 한국국제협력단. 2008. 『국제개발협력의 이해』. 한울 출판사

16) 월드비전, 굿네이버스 등 민간단체의 세계시민 교육교재

17) 2009년 12월 중 발간예정

18) 2007년 교육인적자원부에서 실시한 수도권 대학 특성화 사업 중 “개발협력분야 특성화 사업"으로 경희대학교와 이화여 자대학교가 선정/실시한 바 있다. 
사립대학을 포함하여 17 개 대학 ${ }^{19)}$ 에서 '국제개발협력의 이해' 교과목이 개설되었다는 점은 학부수 준에서 국제개발협력을 다루기 시작하였다는 점과 국제개발협력 분야 인재양성을 위한 중요한 발 판을 마련하였다는 점에서 그 의미가 있다.

국제 개발협력인지강화사업의 세 번째는 각 민간단체에서 실시하는 국제 개발협력 관련 박람회, 워 크샵, 세미나, 콘서트 등에 대한 지원이다. 개별 민간단체들은 최근 개발협력의 중요성과 세계시민 교육 등에 대한 중요성을 인식하면서도 재정적인 부담으로 인하여 개발협력 관련한 교육사업을 본 격적으로 시행하지 못한 것이 사실이다. 그러나 이번 국제개발협력 인지강화사업의 지원으로 전국 20 개 단체(대학, 연구소, $\mathrm{NGO}$ 포함)의 개발협력 인지강화 및 교육사업이 지원받을 수 있게 됨에 따라 한국 사회에서 국제개발협력에 대한 관심과 호응이 촉발할 수 있는 계기를 마련하게 되었다.

\section{나. 민간단체 중심의 국제개발협력 교육}

지금까지 공교육 또는 국제협력단을 중심으로 시행되고 있는 국제개발협력 인지제고 및 교육사업 에 대해 살펴보았다. 이처럼 정부 주도로 이루어지고 있는 개발협력 인지제고 및 교육사업과 동시 에 한편으로는 민간단체(주로 개발협력 $\mathrm{NGO}$ 단체)가 주도적으로 실시하고 있는 개발협력 인지제고 노력 및 교육 프로그램도 또한 증가하고 있다.

민간단체가 주도적으로 실시하는 개발협력 관련 인지제고와 교육사업은 주로 빈곤, 환경, 인권, 평 화 등 국제개발협력과 관련된 주제에 대한 세미나, 캠프, 게임 활동 등의 형태로 진행되고 있다. 2005년 시작된 유니세프 한국위원회의 '나커나' 프로그램이를 시작으로 월드비전, 굿네이버스, 한 국 국제기아대책기구, 지구촌나눔운동, 세계청년봉사단, 한국 해외원조단체협의회 등에서 실시되 는 인지제고 및 교육프로그램이 그것이며, 그 주요 교육대상, 교육내용 및 교육 형태는 〈표 4>와 같다.

민간단체에서 주도적으로 실시하고 있는 개발협력관련 인지제고 및 교육프로그램들은 주로 교과서 및 학교 교과과정에 얽힌 고정적인 틀에서 벗어나 새로운 형태의 창의적 강의를 실시할 수 있다는 장점이 있으며 ${ }^{21)}$, 주로 개발협력에 대한 인지제고보다는 세계시민으로서의 시민의식을 함양하는 쪽 에 초점이 맞추어져 있는 특징이 있다

19) 2009년 "국제개발협력의 이해" 교과목 개설은 강원대학교,대전대학교,동서대학교,배재대학교,숙명여자대학교,순천대학 교, 연세대학교, 예수대학교, 을지대학교, 인하대학교, 조선대학교, 청운대학교, 한경대학교, 한국교원대학교, 한국기술교육대 학교, 한동대학교, 한성대학교 (총 17 개대학 가나다 순)가 선정되었다.

20) 유니세프 한국위원회 www.sharingedu.net

21) 박수연 등 3인. 2007. 「인도주의적 개발교육을 통한 ODA 역량강화」 : 제 4회 국제개뱔협력 논문공모전 우수작 
〈표 4〉NGO를 통한 개발협력 교육 현황

\begin{tabular}{|c|c|c|c|c|}
\hline 단체명 & 교육명 & 교육대상 & 주요교육내용 & 교육형태 \\
\hline \multirow{2}{*}{ 월드비전 } & $\begin{array}{l}\text { 세계시민학교 } \\
\text {-지도밖행군단 }\end{array}$ & 청소년 & 개발,인권,평화,빈곤,타문화이해 & Offline-3박4일캠프 \\
\hline & 교사아카데미 & 교사 & \multicolumn{2}{|l|}{ 상기내용을 지도할 수 있는 contents } \\
\hline \multirow[t]{2}{*}{ 굿네이버스 } & $\begin{array}{l}\text { 세계시민교육 } \\
\text {-One Heart }\end{array}$ & 초등학생 & $\begin{array}{l}\text { 지구촌현실:빈곤,기아,재난 } \\
\text { 국제기관, MDGs, Case Story }\end{array}$ & $\begin{array}{l}\text { Offline-학교방문 } \\
\text { Online-동영상, 게임, 문 } \\
\text { 제풀이 등 }\end{array}$ \\
\hline & $\begin{array}{l}\text { 세계시민교육 } \\
\text {-강사교육과정 }\end{array}$ & 일반인 & $\begin{array}{l}\text { 상기 내용을 지도할 수 있는 교 } \\
\text { 수법 }\end{array}$ & Offline-워크샵 및 스터디 \\
\hline \multirow[t]{2}{*}{ 한국기아대책기구 } & 글로벌시민교육 & $\begin{array}{l}\text { 유치원 } \\
\text { 초등학생 } \\
\text { 청소년 }\end{array}$ & $\begin{array}{l}\text { 빈곤, 기아현황과 원인, 나눔 및 } \\
\text { 실천방법 }\end{array}$ & $\begin{array}{l}\text { Offline-방문교육, 활동체험, } \\
\text { Online-게임 }\end{array}$ \\
\hline & $\begin{array}{l}\text { Perspectives on } \\
\text { World Hunger }\end{array}$ & 대학생이상 & $\begin{array}{l}\text { 빈곤, 통합적개발, 옹호, 개발현 } \\
\text { 장의 소리, 타문화이해 }\end{array}$ & Offline-2박3일캠프 \\
\hline \multirow{3}{*}{ 지구촌나눔운동 } & 지구촌시민학교 & 주부 & $\begin{array}{l}\text { 지구촌나눔운동의 필드국가에 } \\
\text { 대한 구체적인 정보학습:국가현 } \\
\text { 황, 문화, 의식주 등 }\end{array}$ & Offline-8주교육 \\
\hline & $\begin{array}{l}\text { 지구촌대학생프로 } \\
\text { 그램 }\end{array}$ & 대학생 & $\begin{array}{l}\text { 빈곤,환경,인권,평화 } \\
\text { 국제원조활동 및 수행기관 }\end{array}$ & $\begin{array}{l}\text { Offline-캠프,포럼,방문단 } \\
\text { 형태로 연간지속 }\end{array}$ \\
\hline & $\begin{array}{l}\text { 지구촌청소년프로 } \\
\text { 그램 }\end{array}$ & 청소년 & $\begin{array}{l}\text { 현지사회, 역사,문화이해, 워크샵, } \\
\text { 조사연구,봉사활동 }\end{array}$ & Offline-단기봉사 \\
\hline COPION & 글로벌리더십교육 & $\begin{array}{l}\text { 청소년 } \\
\text { 대학생 } \\
\text { 일반인 } \\
\end{array}$ & $\begin{array}{l}\text { 국제사회주요이슈 } \\
\text { 글로벌리더십/문화역사/문화교류 }\end{array}$ & Offline-현지탐방 \\
\hline 유니세프 & 나눔교육 나커나 & 초등학생 & $\begin{array}{l}\text { 나눔경제/세계역사와 문화/사회 } \\
\text { 균형감각 }\end{array}$ & $\begin{array}{l}\text { Online-웝사이트교육컨텐 } \\
\text { 츠이용(12주과정) } \\
\text { Offline-온라인컨텐츠활용 } \\
\text { 하여 강의자료로 사용 }\end{array}$ \\
\hline
\end{tabular}

(자료: 한국 해외원조단체 협의회 조사/발췌)

\section{IV. 향후과제}

지금까지 우리는 한국의 국제개발협력에 대한 인지정도와 또 인지제고 노력 및 교육 프로그램의 현 황에 대해서 살펴보았다. 이제 이를 바탕으로 한국의 국제개발협력의 인지제고 및 교육 프로그램에 대한 나아갈 방향에 대해서 모색해보고자 한다.

첫째, 우리나라의 국제개발협력에 대한 인지제고 및 교육은 우선 그 목표와 정의(용어)를 명확히 할 필요가 있다. 본고에서도 개발협력 인지강화, 국제개발협력 교육, 세계 시민교육 등 다양한 용 어를 번갈아 사용하는 등 그 목표와 정의(용어)가 명확하게 통일되지 못하여 혼란을 겪고 있는 것 이 사실이다. 이는 아직까지 우리나라의 국제개발협력에 대한 낮은 인지정도, 개발협력 교육에 대 
한 인식부재, 세계 시민교육의 목표와 정의(용어)에 대한 명확한 기준이 서지 않은데서 기인하며, 이를 해결하기 위한 노력이 선행되어져야 할 것으로 보인다. 최근 네덜란드, 노르웨이, 스웨덴, 영 국, 아일랜드 등 개발교육(Development Education)이 활발하게 진행되는 선진국에서 개발인지 (Development Awareness)의 확산이라는 협의의 개념보다는 세계시민교육(Education for Global Citizenship) 이라는 교육적 관점에서 접근하고 있는 사실 ${ }^{22}$ 은 우리의 개발협력 인지제고 및 교육 의 목표와 기준을 세우는데 참고가 될 수 있다 하겠다.

둘째, 우리나라는 현재까지 국제개발협력 교육에 대한 장기적인 로드맵이 형성되어 있지 않다. 현 재 초·중·고등학교에 게재되고 있는 국제개발협력 또는 세계시민으로서의 의식에 대한 내용이 장기적인 안목과 로드맵 속에서 이루어지고 있다고 보기 어렵고 또한, 국제협력단에서 실시하고 있 는 “국제개발협력 인지강화 프로그램” 은 그 제목에서도 알 수 있듯이 국제개발협력에 대한 국민의 이해와 인지제고를 그 목적으로 하고 있어 장기적 로드맵이라고 보기는 어렵다. 이에 필자는 현재 단계의 개발협력 인지강화단계를 시작으로 성숙한 세계시민의식 함양 단계로 나아가는 〈그림 1)과 같은 로드맵을 제시하며, 이와 같은 장기적 로드맵 수립을 바탕으로 체계적· 효과적인 개발협력 인 지제고 및 교육프로그램 실시를 제안하는 바이다.

\section{〈그림 1〉 국제개발협력 교육 로드맵}

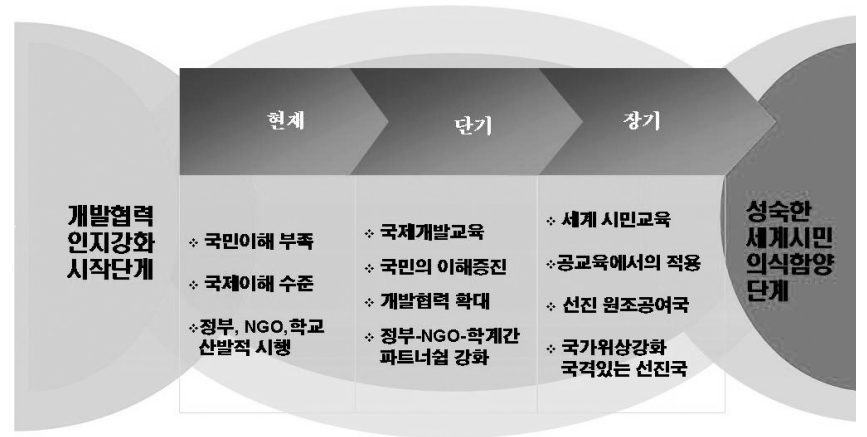

셋째, 국제개발협력 또는 세계시민 의식 함양을 위한 교육과학기술부, 외교통상부(국제협력단 포 함), 민간단체를 포함한 민-관(民官)합동 “세계시민교육위원회”(가칭) 등의 창설을 통해 국가 전체 차원의 정책수립과 교육시행 등의 협력이 필요하다고 본다. 영국의 경우, 국제개발부(Department for International Development; DFID), 아동교육가족부(Department for Children, schools and families), 국정교과서 편찬위원회(Qualifications and Curriculum Authority; QCA) 등의 정부기관과 개발교육협의회(Development Education Association; DEA), Oxfam 등의 민간단체

22) Douglas Bourn. 2008. 『Development Education Debates and dialogues』. Institute of Education. London 
가 함께 국제개발분야 및 세계시민교육의 커리큘럼 개발에 유기적으로 협력하고 이를 바탕으로 개 발협력교육이 왕성하게 실시 ${ }^{23)}$ 되고 있어 이제 개발협력 교육을 체계적으로 시작하려 하는 우리나라 에게 많은 시사점을 가져다준다.

넷째, 올해 국제협력단을 통하여 국제개발협력에 대한 인지제고 프로그램이 도입된 것은 시의적절 하고 환영할 만한 것이나, 만약 국제개발협력 인지강화 프로그램이 2009년 일회성 사업으로 끝날 경우에는, 일시적이고 단발적인 관심과 과시성 지원으로 끝날 우려가 있다. 보다 장기적이고 지속 적인 지원과 교육을 통해 국제개발협력에 대한 국민의 보다 근본적인 이해와 성숙한 시민의식을 함 양할 필요가 있다 하겠다. 이를 위해 국제개발협력 인지강화 프로그램에 대한 예산확보와 증대가 수반되어져야 할 것이다.

다섯째, 현재까지 우리나라에서는 국제개발협력에 대한 교육을 전담적으로 실시하고 있거나 특화 되어 실시하고 있는 기관 및 단체가 없는 실정이다. 영국과 아일랜드등의 유럽국가 ${ }^{24}$ 는 물론이거니 와 일본의 경우도, JICA에서 운영하는 개발교육연구센터와 민간차원의 개발교육협의회가 있어 국 제개발협력에 대한 교육 컨텐츠를 개발하고 지속적인 연구와 교육을 실시 ${ }^{25}$ 함으로써 국제개발협력 교육에 대한 효과를 높이고 있다. 우리나라 역시 이와 같은 “국제 개발협력 교육 연구센터”와 “국 제 개발교육협의회”(가칭) 창설을 통해 지속적인 연구와 효과적인 교육지원이 필요하다 하겠다. 또 한 현재까지 우리나라의 국제개발협력 교육은 대동소이 비슷한 내용과 분야에 대한 비슷한 형식의 교육을 실시하고 있어, 각 분야별로 전문화되고 특성화된 다양한 방식의 개발협력 교육이 이루어져 야 할 것으로 보인다.

여섯째, 위에서 필자가 제시한 세계시민 교육위원회(가칭), 국제 개발협력 교육 연구센터 및 개발교 육 협의회(가칭)등을 통하여 한국 상황에 맞는 교육 프로그램 및 컨텐츠 개발이 이루어져야할 것이 다. 현재까지 우리나라의 개발협력 교육 프로그램은 영국, 일본 등에서 실시되어져오고 있는 교육 프로그램에 대한 번역 및 재교육 등 선진국 프로그램에 대한 벤치마킹 수준에서 이루어지고 있어 한국의 실정, 문화, 특성에 맞는 교육 프로그램에 대한 개발과 지원이 이루어져야 하겠다.

마지막으로, 현재까지 우리나라에서 실시되어지고 있는 국제개발협력 분야 교육은 정부, 민간단체 (NGO), 학계, 학교 등에서 산발적으로 이루어지고 있어 이에 대한 유기적이고 통합적인 협의 및

23) 영국 개발협력교육협의회(DEA)의 Developing the global dimension in the school curriculum 및 교과서편찬위원회(QCA) 의 The global dimension in action 등 개발교육 교재 이용

24) 국의 Development Education Association(DEA), 아일랜드의 Irish Development Education Association(IDEA)

25) 최민경. 2008. 『국제개발협력 전문인력 육성 및 활용방안에 관한 연구』한국국제협력단. 
협조체계가 필요하다 하겠다. 정부의 명확한 목표와 방향성, 예산지원 등을 바탕으로 민간단체의 자발성 및 현장성이 뒷받침되어지고 학계와 학교에서의 효과적인 연구 및 실질적인 교육이 이루어 질 때 국제개발협력 교육에 대한 시너지 효과가 일어날 수 있을 것으로 기대된다.

요컨대, 교육은 “百年之大計”라 하여 예로부터 미래를 위한 중요한 초석이라고 여겨져 왔다. 경제 성장과 민주주의의 발전에 힘입어 이제 선진국으로 발돋움하고 있는 우리나라의 경우, 국제개발협 력과 세계시민 교육은 대한민국의 미래를 결정할 수 있는 중요하고도 의미 있는 일이다. 현재 우리 나라의 국제개발협력 교육이 시작단계이다 하더라도 지금부터 국제개발협력 교육에 대한 명확한 목표와 정의를 바탕으로 장기적이고 지속적인 로드맵을 수립하고 정부와 민간단체, 학계, 학교 등 이 유기적으로 협조해나갈 때 우리의 국제개발협력 교육은 선진화할 것이며, 나아가 대한민국은 국 제사회에서 품격 있는 국가로 자리매김해 나갈 수 있을 것이다. 


\section{참고문헌}

\section{1. 국내문헌}

교육부 고시 제 1997-15호 제 7차 교육과정

굿네이버스. 2008. 『One Heart』: 굿네이버스 세계시민교육 교재

김은미. 2009.「국민인식 제고와 $\mathrm{NGO}$ 와의 협력방안」. $\mathrm{OECD} / \mathrm{DAC}$ 가입과 우리 대외원조의 개선방안’ 세미나 발제자료

박선영. 2009.「지구시민교육의 역사와 현황; 영국사례를 중심으로」. 제 3회 지 구촌 포럼 “국제개발협력 증진을 위한 대중인식 제고 활동의 현황과 방향” 발표자료

박수연 외. 2007. 「인도주의적 개발교육을 통한 ODA 역량강화」 : 제 4회 국제개 발협력 논문공모전 우수작

오무석. 2002.「韓 ·日 國際開發NGO에 관한 比較硏究」 : 경희대학교 NGO 대 학원 석사학위 논문

이삼열. 2003.『세계화 시대의 국제이해교육』. 한울아카데미

전승훈 외. 2008. 「개발원조에 대한 대국민 여론조사 및 정부의 국제개발협력정책 의 방향연구」. 한국개발전략연구소

최민경. 2008. 「국제개발협력 전문인력 육성 및 활용방안에 관한 연구」. 한국국 제협력단

최민경. 2008. 「우리나라 개발원조의 민관협력 활성화 방안 : $\mathrm{PPP}$ 와 개발컨설턴 트 활용을 통한 민간과의 파크너십 강화」. 한국국제협력단.

한국국제협력단. 2008.『국제개발협력의 이해』. 한울출판사

Hyun-sik Chang. 2007. 「Strategies on Raising Public Awareness in South Korea : How to build public and political support for development assistance」. Workshop on Public Awareness and Support of ODA 워 크샵 발표자료 


\section{2. 외국문헌}

DEA. 2009. Our Global Future Policy Recommendations

DEA. 2005. Developing the global dimension in the school curriculum

Douglas Bourn. 2008. "Development Education Debates and Dialogues". Institute of Education. London

Oxfam. 1997. A Curriculum for Global Citizenship

Oxfam. 2006. Education for Global Citizenship- A Guide for schools

Pete Davis. 2007. "Development Education and the School Curriculum - Synthesis of the report on the status of development education in the formal education sector and school curriculum in countries of the European Union"

John Gaventa and Marjorie Mayo. 2009. Spanning Citizenship Spaces Through Transnational Coalitions : The Case of the Global Campaign for Education. Working Paper Volume 2009 Number 327 ; IDS

QCA. 2007. The global dimension in action

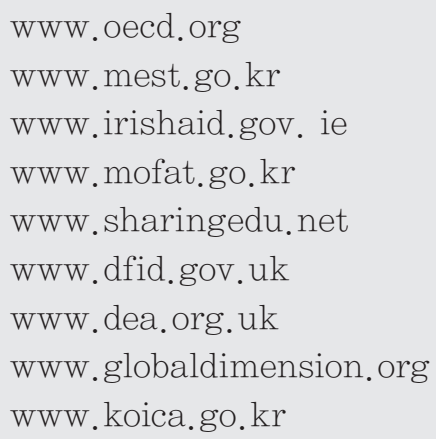

